\title{
The knowledge, attitude and practices of Turkish general dentists on dental $x$-rays in pregnant women
}

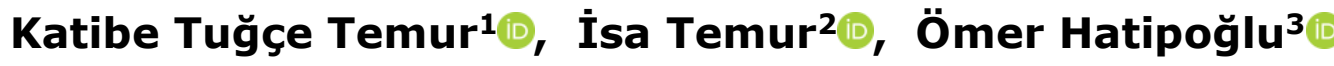 \\ ${ }^{1}$ Kahramanmaraş Sütçü İmam University, Faculty of Dentistry, Department of Oral and Maxillofacial Radiology, Kahramanmaraş, \\ Turkey. \\ ${ }^{2}$ Necip Fazıl City Hospital, Department of Obstetrics and Gynecology, Kahramanmaraş, Turkey. \\ ${ }^{3}$ Kahramanmaraş Sütçü İmam University, Faculty of Dentistry, Department of Restorative Dentistry, Kahramanmaraş, Turkey.
}

\section{Correspondence:}

\section{Dr. Katibe Tuğçe TEMUR}

Kahramanmaraș Sütçü İmam University, Faculty of Dentistry, Department of

Oral and Maxillofacial Radiology,

Kahramanmaraș, Turkey.

E-mail:tugcetemur@ksu.edu.tr

Received: 16 October 2018

Accepted: 22 February 2019

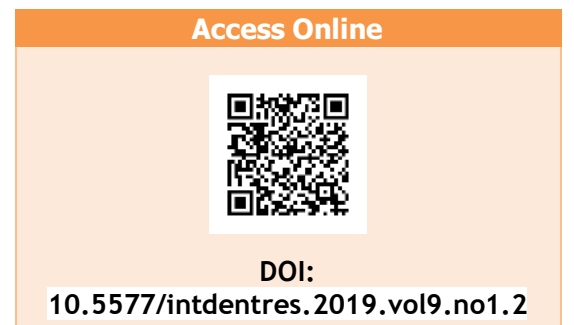

10.5577/intdentres.2019.vol9.no1.2

\section{Abstract}

Aim: The purpose of this study was to evaluate the knowledge, attitude and practices of the general dental dentists working in Turkey on the dental $\mathrm{x}$-rays in pregnant women; and to develop awareness for the purpose of not delaying their dental treatments.

Methodology: The questionnaire that was used in the study was applied to 270 dental dentists who worked in Turkey in electronic medium. The questionnaire consisted of 2 sections each of which had 11 questions. In the first section, the demographical data were questioned. In the second section, there were questions to determine the knowledge, attitude and practices of the dentists on x-ray in pregnant women. The questionnaires that were completed were examined and analyzed statistically by using the results and the Chi-Square Test and the Chi-Square Test.

Results: A total of $71.1 \%$ of the dental practitioners who participated in the study stated that they did not request radiography from pregnant women. A total of $62.2 \%$ of the dental dentists stated that they preferred the 2nd Trimester for requesting radiography. A total of $38.9 \%$ of the general dentists who participated in the study stated that the diagnostic radiographies used in dentistry caused anomalies in the fetus, $18.9 \%$ stated that they did not have any information.

Conclusions: Further training courses must be planned to increase and update the awareness of the dental dentists on the precautions and procedures for radiography practice in pregnant women; and brochures must be prepared for pregnant women to provide information about this subject. Also, dental dentists and obstetricians should work in agreement about dental procedures in pregnancy and diagnostic radiography in terms of its being safe when necessary.

Keywords: General dentists, pregnancy, dental radiography, knowledge, attitude, practices

How to cite this article: Temur KT, Temur İ, Hatipoğlu Ö. The knowledge, attitude and practices of Turkish general dentists on dental $x$-rays in pregnant women. Int Dent Res 2019;9(1):9-15.

\section{Introduction}

Physical changes that appear in pregnancy may increase the tendency of a woman to oral infections, including periodontal disease. It may also damage the ability in the body in protecting soft tissues in the mouth. In addition, dental cavities may increase because of changing oral hygiene and diet in pregnancy (1). Pregnant women visit dentists for pains related to tooth, infections in the soft tissues of the mouth, and other infections. Radiography is usually required before 
dental treatment in pregnant women. As dentists do not have adequate knowledge on low doses included in diagnostic dental radiation, they have the tendency to postpone the dental treatment of pregnant women to postpartum period. Dental treatment delays may cause negative effects on the mother and the fetus (2).

Embryos and fetuses are more radiosensitive compared to adults as most of the embryonic cells are relatively not differentiated and are mitotic in a fast pace. It is considered that being exposed to radiation within 2-3 Gy range on the first few days after the fertilization ends up with the death of the embryo. Many of these embryos cannot be implanted onto the uterine wall. In pregnancy, this kind of response against radiation is the result of a very high dose. Nearly $5 \%$ of live births show a congenital anomaly without any exposure to radiation. It is estimated that being exposed to radiation at a rate of one 10th (100mGy) causes that there is an increase in congenital anomalies in percentile terms. Since diagnostic dose is lower than 10 in dentistry, it was reported previously that these kinds of anomalies cannot be associated with dental diagnostic doses (3).

Kusama et al. estimated that the fetus did not receive the radiation doses directly in a head and chest radiography; and that the dose that was absorbed was less than $0.01 \mathrm{mGy}$. They concluded that it was not necessary to end the pregnancy in case the exposure doses of the fetus were lower than $100 \mathrm{mGy}$ in pregnant women who are exposed to radiation and who are not aware of their pregnancies (4).

In addition to these, according to the American Dentists' Association and the American College of Obstetricians and Gynecologists, the necessity of having dental $\mathrm{x}$-ray in pregnancy is considered safe provided that it is carried out with proper protection which does not cause any side effects for a growing embryo or fetus (5). However, no radiographies must be carried out in pregnant women as long as it is an definite requirement. All measures must be applied to minimize the dose that might be absorbed when these radiographies are absolute necessary. By considering the above mentioned principles, and by observing the doses included in the diagnostic procedures and knowing the safest time for radiography, pregnant women may have the opportunity to undergo radiographic techniques in pregnancy. Using aprons that are made of lead may reduce the radiation doses as low as at a rate of $98 \%$. In pregnant women, the maternal tissues that cover the fetus decrease the dose the fetus might be exposed to $30 \%$ of the abdominal cutaneous dose (6).

The purpose of this study is to determine the knowledge, attitude and practice of general dentists working in Turkey about dental $\mathrm{x}$-rays in pregnant women. Another purpose of it is to develop awareness to ensure that the necessary dental treatments of pregnant women are not postponed.

\section{Materials and Methods}

In this study, a questionnaire was applied electronically to 270 dentists who worked actively in Turkey. The study was conducted between June 2018 and August 2018. Prior to the study, approval was received from Kahramanmaraș Sütçü Imam University, Faculty of Medicine, Clinical Research Ethics Committee. Informed consent forms were received from the dentists who participated in the study.

The questionnaire form consisted of a total of 15 questions in 2 sections.

1- General data on age, gender, and professional experience were questioned in the first section.

2- In the following section, there were questions that aimed to evaluate the knowledge, attitude and practices of the general dentists on dental $x$ rays.

The sample of the questionnaire is shown in Table-1.

Table 1. The survey form.

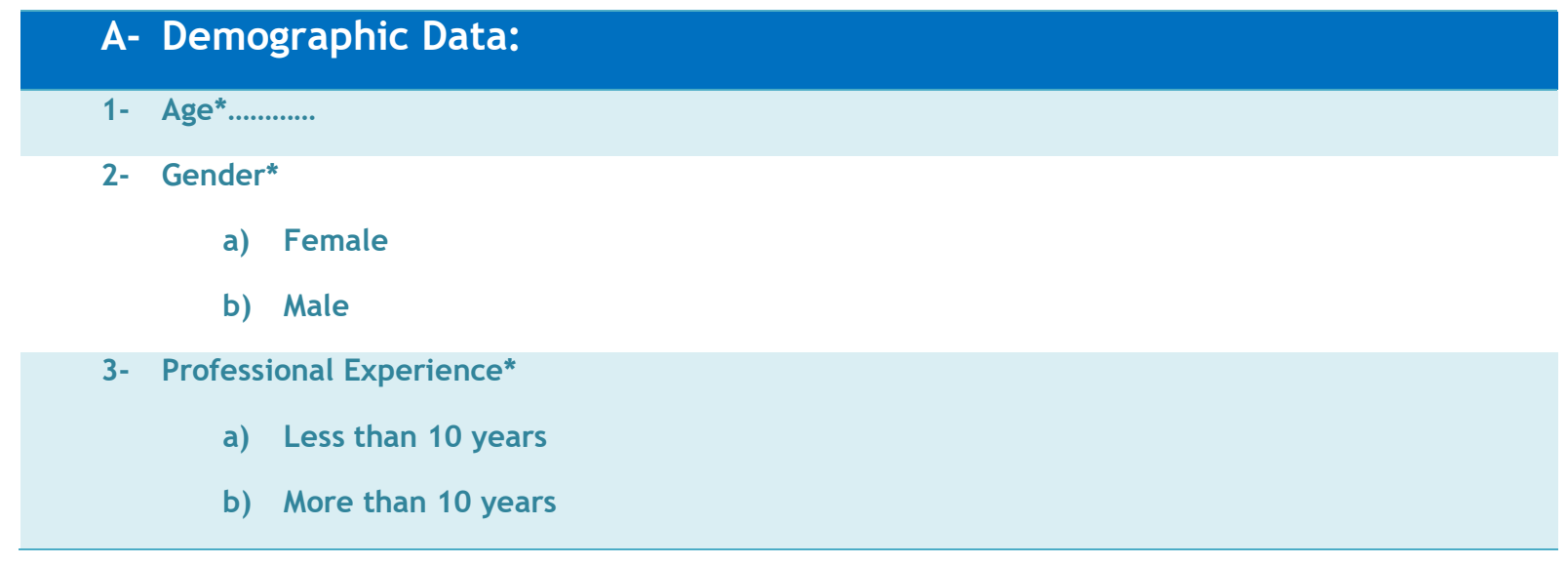


B- The Knowledge, Attitude and Practices of Dentists on Dental Radiography in Pregnant Women:

1- Do you request radiography from pregnant women?
a) Yes
b) No

2- Radiography is contraindicated in pregnant women?
a) Yes
b) No
c) I do not know

3- If you request radiography from pregnant women, what kind of precautions do you take?
a) Lead apron
b) Triode protector
c) Both
d) None

4- Does diagnostic radiation doses in dentistry cause anomalies in the fetus mu?
a) Yes
b) No
c) I do not know

5- What is the most suitable period for dental radiography in pregnant women?
a) The $1^{\text {st }}$ Trimester
b) The $2^{\text {nd }}$ Trimester
c) The Third Trimester
d) I do not know

6- Which imaging method do you prefer in pregnant women?
a) Periapical
b) Panoramic
c) $\mathrm{CBCT}$

7- At which speed do you use the film for periapical radiography?
a) $\mathrm{D}$
b) $E$
c) $\mathrm{F}$
d) I do not know

8- Do you know the ALARA principle?
a) Yes
b) No 


\section{Statistical Analysis}

Completed questionnaires were examined and statistically analyzed using the results and chi-square test. Data analysis was performed using Statistical Package for the Social Sciences version 23.0 (SPSS Inc., Chicago, IL, USA). The probability level for statistical significance was determined as $p=0.05$.

\section{Results}

A total of 270 general dentists 159 of whom were female, and 111 were male. The average age of the general dentists who participated in the study was 33.7. It was determined that the number of those who had less than 10 years' professional experience was 156 , and the ones that had over 10 years of experience was 114 (Table-2).

A total of $71.1 \%$ of the general dentists who participated in the study stated that they did not request radiography from pregnant patients, and $74.4 \%$ stated that requesting radiography from pregnant women was not contraindicated.

A total of $38.9 \%$ of the general dentists who participated in the study stated that the diagnostic radiographies used in dentistry caused anomalies in the fetus, $18.9 \%$ stated that they did not have any information.

A total of $71.1 \%$ of the general dentists, who requested radiography from pregnancy women stated that they made the patient to wear both thyroid protector suit and lead apron. They also stated that they mostly used F-type films, and $44 \%$ stated that the radiation dose was reduced when they used high-speed films.

A total of $62.2 \%$ of the general dentists stated that the 2 nd Trimester was the best period for radiography. On the other hand, a total of $57.8 \%$ of the general dentists stated that they preferred the most common periapical $\mathrm{x}$-ray as the radiographic method in pregnant women.

A total of $74.4 \%$ of the general dentists stated that they know the ALARA principle (Table-3).

In the present study, it was determined that the dentists, who had more than 10 years' professional experience, requested radiography more frequently $(p<0.001)$. However, there was no significant differences between genders.

A total of $83.0 \%$ of the female dentists, who were included in the present study, stated that radiography from pregnant women was not a contraindication $(p<0.001)$.

It was found that there was a significant difference between the precautions taken during radiography and the professional experience. While $62.5 \%$ of the general dentists who used both the triode protector (collar) and the lead apron had a professional experience lower than 10 years, $37.5 \%$ of them had more than 10 years' professional experience. It was determined that there was a significant difference between the precautions taken during radiography and gender. While $65.6 \%$ of those who used both triode protector (collar) and collar in pregnant women together were female, $34.4 \%$ were male general dentists $(p<000.1)$.

The professional experience year of the general dentists, who considered that dental radiography may cause anomalies in the fetus, had an effect at a significant level $(p<0.001)$. A total of $57.1 \%$ of the general dentists, who considered that dental radiography may cause anomalies in the fetus, had less than 10 years' professional experience.

The gender factor affected the most appropriate period for radiography in pregnant women at a significant level. A significant difference was detected between the choice of radiography method and gender.

The gender factor also affected those who knew the ALARA principle (Table-4).

Table-2: Distribution of General Turkish Dentists $(n=270)$ according to gender, experience.

\begin{tabular}{cccc} 
Demographic features & Factors & $\mathbf{n}$ & $\%$ \\
\hline \multirow{2}{*}{ Gender } & Male & 111 & 41,1 \\
& Female & 159 & 58,8 \\
\hline \multirow{2}{*}{ Experience } & $\leq 10$ Years & 156 & 57,7 \\
& $>10$ Years & 114 & 42,2
\end{tabular}


Table-3: Practices, Knowledge and Attitudes of General Turkish Dentists in towards radiographs in pregnant women.

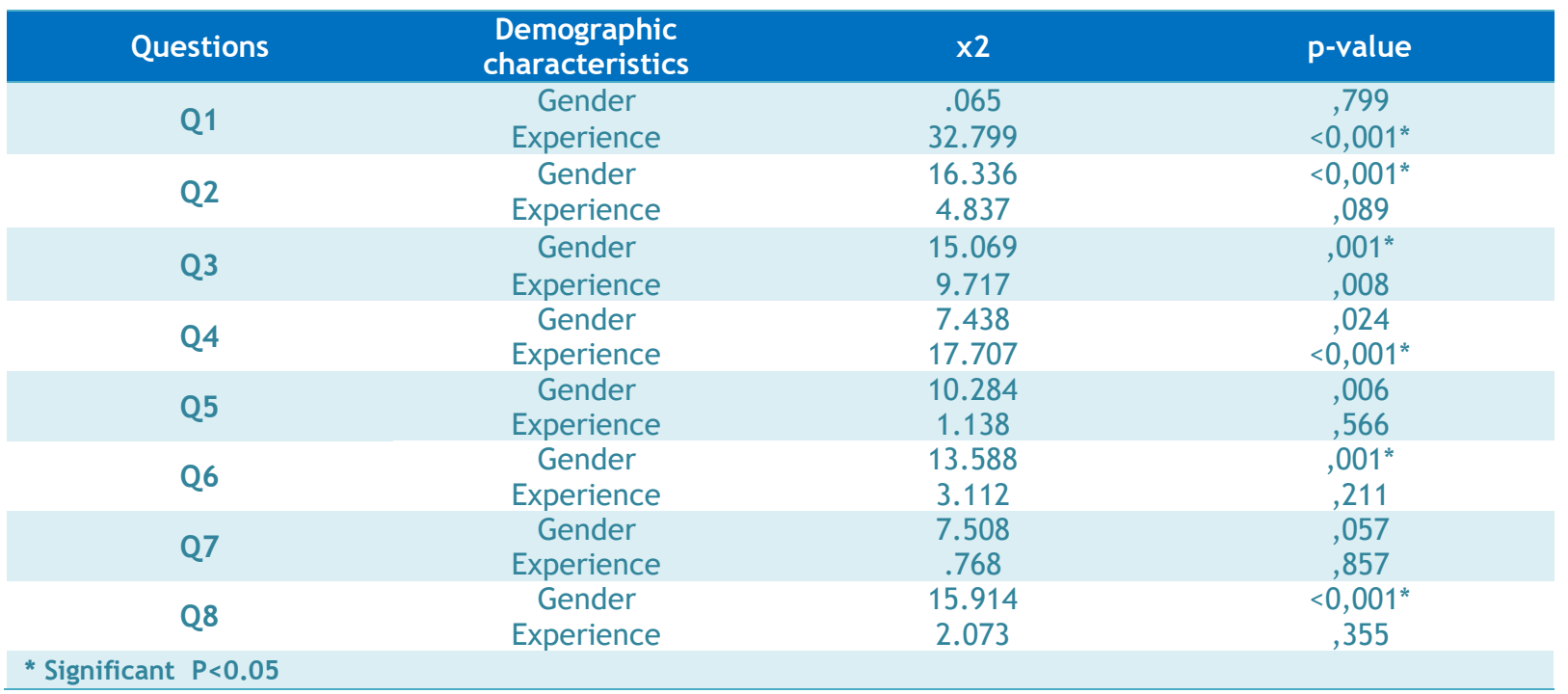

Table-4: Statistical data between the participants' demographic characteristics and the factors (Pearson's x2 tests).

\begin{tabular}{|c|c|c|c|c|c|c|}
\hline ACTORS & SUBGROUPS & \multicolumn{2}{|c|}{ GENDER } & \multicolumn{2}{|c|}{ EXPERIMENT } & TOTAL \\
\hline & & Male & Female & $<10$ Years & $>10$ Years & \\
\hline \multirow{2}{*}{ Q1 } & Yes & $29.7 \%$ & $28.3 \%$ & $15.4 \%$ & $47.4 \%$ & $28.9 \%$ \\
\hline & No & $70.3 \%$ & $71.7 \%$ & $84.6 \%$ & $52.6 \%$ & $71.1 \%$ \\
\hline \multirow{3}{*}{ Q2 } & I do not know & $13.5 \%$ & $3.8 \%$ & $7.7 \%$ & $7.9 \%$ & $7.8 \%$ \\
\hline & Yes & $24.3 \%$ & $13.2 \%$ & $13.5 \%$ & $23.7 \%$ & $17.8 \%$ \\
\hline & No & $62.2 \%$ & $83.0 \%$ & $78.8 \%$ & $68.4 \%$ & $74.4 \%$ \\
\hline Q3 & $\begin{array}{c}\text { Lead Apron } \\
\text { Thyroid Protector } \\
\text { None } \\
\text { Both of them }\end{array}$ & $\begin{array}{c}8.1 \% \\
0 \% \\
32.4 \% \\
59.5 \%\end{array}$ & $\begin{array}{c}7.5 \% \\
0 \% \\
13.2 \% \\
79.2 \%\end{array}$ & $\begin{array}{c}3.8 \% \\
0 \% \\
19.2 \% \\
76.9 \%\end{array}$ & $\begin{array}{l}13.2 \% \\
0 \% \\
23.7 \% \\
63.2 \%\end{array}$ & $\begin{array}{c}7.8 \% \\
0 \% \\
21.1 \% \\
71.1 \%\end{array}$ \\
\hline \multirow{3}{*}{ Q4 } & I do not know & $21.6 \%$ & $17.0 \%$ & $26.9 \%$ & $7.9 \%$ & $18.9 \%$ \\
\hline & Yes & $45.9 \%$ & $34.0 \%$ & $38.5 \%$ & $39.5 \%$ & $38.9 \%$ \\
\hline & No & $32.4 \%$ & $49.1 \%$ & $34.6 \%$ & $52.6 \%$ & $42.2 \%$ \\
\hline \multirow{4}{*}{ Q5 } & I do not know & $35.1 \%$ & $18.9 \%$ & $26.9 \%$ & $23.7 \%$ & $25.6 \%$ \\
\hline & 1. Trimester & $0 \%$ & $0 \%$ & $0 \%$ & $0 \%$ & $0 \%$ \\
\hline & 2. Trimester & $56.8 \%$ & $66.0 \%$ & $59.6 \%$ & $65.8 \%$ & $62.2 \%$ \\
\hline & 3. Trimester & $8.1 \%$ & $15.1 \%$ & $13.5 \%$ & $10.5 \%$ & $12.2 \%$ \\
\hline \multirow{3}{*}{ Q6 } & Periapical & $45.9 \%$ & $66 \%$ & $53.8 \%$ & $63.2 \%$ & $57,8 \%$ \\
\hline & OPG & $45.9 \%$ & $32.1 \%$ & $40.4 \%$ & $34.2 \%$ & $37,8 \%$ \\
\hline & $\mathrm{CBCT}$ & $8,1 \%$ & $1.9 \%$ & $5.8 \%$ & $2.6 \%$ & $4.4 \%$ \\
\hline \multirow{4}{*}{ Q7 } & I do not know & $73.0 \%$ & $60.4 \%$ & $67.3 \%$ & $63.2 \%$ & $65.6 \%$ \\
\hline & D & $8.1 \%$ & $5.7 \%$ & $5.8 \%$ & $7.9 \%$ & $6.7 \%$ \\
\hline & $E$ & $8.1 \%$ & $15.1 \%$ & $11.5 \%$ & $13.2 \%$ & $12.2 \%$ \\
\hline & $\mathrm{F}$ & $10.8 \%$ & $18.9 \%$ & $15.4 \%$ & $15.8 \%$ & $15.6 \%$ \\
\hline \multirow{2}{*}{ Q8 } & Yes & $56.8 \%$ & $86.8 \%$ & $82.7 \%$ & $63.2 \%$ & $74.4 \%$ \\
\hline & No & $43.2 \%$ & $13.2 \%$ & $17.3 \%$ & $36.8 \%$ & $25.6 \%$ \\
\hline
\end{tabular}




\section{Discussion}

According to a great number of studies included in the literature, a high percentage of dentists are not sure of how to proceed in terms of radiography for a pregnant patient and are in doubt (7). However, the teratogenicity of radiation depends on its dosage. When exposure to radiation is higher than $500 \mathrm{mGy}$, it causes fetal damage. The most sensitive period for the central nervous system harm caused by radiation is 815 weeks following the fertilization. microcephaly, mental retardation, mental disorders, or induction of childhood malignancies are among the negative fetal effects that are associated with exposure to radiation (8).

Provided that the basic principles of exposure to radiation are covered dental radiographies are safe at any time in pregnancy. Urgent dental treatment may be carried out at any time in pregnancy. However, there may be additional problems associated with positional disease and vena cava compression risk in the 3rd Trimester (9). It is stated in another source in the literature that in all cases that necessitate imaging in pregnant women, only the radiographies that are necessary for the diagnosis and treatment may be carried out by considering the ALARA principle (10). The teratogenic threshold dose risk related to any dose that is related to dentistry is given as 1000 -fold lower, $0.1 \%$ or lower than the spontaneous abortus and malformation risk (11).

In the present study, a total of $71.1 \%$ of the Turkish general dentists stated that they did not request radiography in pregnant women; and $42.2 \%$ of them stated that dental X-rays could cause anomalies in the fetus. In addition, $74.4 \%$ of the general dentists stated that dental $X$-rays were not contraindicated in pregnant patients. In a study that was conducted by Wali et al. on maxillofacial surgeons, it was reported that $169(64 \%)$ of them stated that radiographs were harmful for pregnant women (11). In a study conducted by Prasad et al., it was reported that 240 (96\%) of the dentists stated that radiographies were harmful for pregnant women (12). In a study conducted by Razi et al., $28.4 \%$ of the dentists reported that diagnostic radiation doses would not cause developmental anomalies or mental retardation in fetuses (2).

Even if ionizing radiation is teratogenic, the careful use of dental radiographies is not a contraindication in pregnancy. However, in a pregnant patient who will undergo radiography, dental radiography is not contraindicated provided that highspeed films, shielded collimation, filtering, and most important than all, a lead apron are used to minimize the exposure to radiation for the patient. Although the fetal dose that is estimated for a chest $x$-ray is 0.008 cGy (centiGrays), the radiographies of traditional teeth with full mouth intra-oral exposure, D-speed film and routine precautions) cause that the fetus is exposed to an estimated 0.00001 . CGy. By using use newer $\mathrm{E}$-speed films, the exposure to radiation is decreased at a rate of $50 \%$. A series with full mouth is not indicated for pregnant women in general; however, for a satisfactory diagnosis of a certain dental problem, one or two intraoral exposures may be carried out safely with appropriate precautions (13).

In the study that was conducted by Razi et al., a total of $92 \%$ of the dentists were aware of the requirement of using lead aprons in radiography; and $18 \%$ of them believed that F-speed films should be used. 2 In this study, it was reported that a total of $71.1 \%$ of the Turkish dentists used both triode protectors and lead aprons when they were carrying out radiography; and $15.6 \%$ of them preferred $\mathrm{F}$-type films. Again, in another study, similar to this study, it was reported that $70.4 \%$ of the dentists stated that precautions should be taken when carrying out radiography in pregnant patients (12). Pregnant women should not be exposed to radiological procedures unless there appears a certain necessity to be considered. When these procedures are carried out, all the precautions must be applied to lower the radiation dose to the lowest rate. It must be known that using a lead apron decreases the radiation dose at a rate of up to $98 \% .3$

In the literature, it is recommended that radiography in pregnancy is postponed until the 2 nd Trimester in urgent situations. The radiographies carried out for routine follow-ups are best carried out after the delivery (15). A total of $62.2 \%$ of the general Turkish dentists, who participated in the present study, stated that they preferred the 2nd Trimester. In a study conducted by Prasad et al., similar to this study, a total of $39(52.7 \%)$ of the dentists carried out diagnostic radiography in the 2 nd Trimester (12). Braimoh 0 . et al. reported that a total of 44 of the dental surgeons $(60 \%)$ knew that the best period for dental radiography was the 2 nd Trimester in pregnancy (14). Zanata et al. reported that $16.2 \%$ and $37.8 \%$ of dentists knew that dental radiographies are safe throughout pregnancy, and that dental radiographies are best carried out in the 2nd Trimester (15). A similar study that was conducted in Connecticut for the purpose of evaluating general dentists reported that most dentists $(77 \%)$ would carry out a radiography in pregnancy (in the 2 nd Trimester) to plan a treatment for dental pain $(16,17)$.

Wali reported that a total of 109 of dental surgeons $(41.3 \%)$ applied the ALARA principle (11). In another study, Prasad et al. reported that a total of 132 $(52.8 \%)$ of the dental surgeons applied the ALARA principle (12). It was reported that $74.4 \%$ of the Turkish dentists, who participated in the study, applied the ALARA principle.

A total of $57.8 \%$ of the dentists, who participated in this study, reported that they preferred the periapical Radiography. In the literature, it was reported that the risk of being exposed to teratogenic radiation through intraoral films is 1000 -fold less than the risk of natural spontaneous abortion or malformation (14). George et al. conducted a study in New South Wales in Australia and applied a questionnaire to determine the knowledge, attitude and practices of dentists in mouth hygiene in pregnancy. They reported that $82.2 \%$ of the dentists did not request full mouth radiography; and $63.2 \%$ stated that they sometimes carried out single periapical 
radiography. On the other hand, in the same study, it was also reported that the dentists stated that they would like to receive more training to provide service to pregnant women, and $96.8 \%$ stated that there was a need for universal rules for all healthcare employees in mouth hygiene in pregnancy.

No detailed reports exist on dental radiography applications in pregnant women and on how some variables like socio-demographic data and professional experience affect the knowledge, attitude and practices of the dentists. In the present study, it was seen that female dentists have more accurate knowledge and practices compared to their male colleagues at a significant level about the radiological procedures in pregnant patients. This situation may be associated with the fact that female dentists are more sensitive about the potential harmful effects of radiography on the fetus and on female reproductive organs. In a study that was conducted in Finland, it was reported that female dentists considered protection from radiation as more important than their male colleagues (18). No previous reports have been released on how socio-demographic variables affect the knowledge, attitude and practices of dentists for dental radiography in pregnant women; and further studies are necessary to understand this issue better.

On the other hand, the general dentists who have a professional experience more than 10 years did not refrain from carrying out dental radiography in pregnant patients at a significant level compared to the dentists who were less experienced, and knew that this did not cause harmful effects on the fetus. This may be explained with the fact that experienced dentists tend to show more conscious attitudes about health issues. Further studies are required to cast more light on this relation.

\section{Conclusions}

Further training courses should be planned for the purpose of increasing the awareness of dentists on the precautions and procedures in radiography practices for pregnant women, and to update their knowledge; and informative brochures should be prepared for pregnant women on this subject. On the other hand, dentists and gynecologists should act in agreement about the dental procedures in pregnancy and, where necessary, about the safety of diagnostic radiography.

Ethical Approval: Ethics committee approval was received for this study from Kahramanmaraș Sütçü Imam University, Faculty of Medicine, Clinical Research Ethics Committee.

Peer-review: Externally peer-reviewed.

Author Contributions: Conception - K.T.T., I.T.; Design - K.T.T., I.T., Ö.H.; Supervision-I.T.; Materials-K.T.T., Data Collection and/or Processing - K.T.T., Ö.H.; Analysis and/or Interpretation - K.T.T., Literature Review K.T.T., Writer-K.T.T., Critical Review-I.T, Ö.H.

Conflict of Interest: No conflict of interest was declared by the authors.
Financial Disclosure: The authors declared that this study has received no financial support.

\section{References}

1. Shagana J.A, Kumar R.P. Oral health care during pregnancy: A strategies and considerations Journal of Pharmacy Research. 2018;12:684-8.

2. Razi T, Bazvand L, Ghojazadeh M. Diagnostic dental radiation risk during pregnancy: awareness among general dentists in Tabriz. J Dent Res Dent Clin Dent Prospects. 2011; 5:67-70.

3. White SC, Pharoah MJ, editors. Oral Radiology: Principles and Interpretation. St. Louis: Mosby; 2009.

4. Kusama T, Ota K. Radiological protection for diagnostic examination of pregnant women. Congenit Anom (khoto) 2002;42:10-4. (Crossref)

5. ACOG Committee on Obstetric Practice. ACOG committee opinion. Number 299, september 2004 (replaces no 158, september 1995). Guidelines for diagnostic imaging during pregnancy. Obstet Gynecol 2004;104:647-51. (Crossref)

6. Stewart C, Bushong SC, editors. Radiologic Science for Technologists. St. Louis: Mosby; 2004.

7. Vieira DP, de Oliveira AF, Lopes FF, de Figueiredo M, e MaiaL. Dentists' knowledge of oral health during pregnancy: Areview of the last 10 years' publications. Community Dent Health 2015;32:77-82.

8. Bentur $\mathrm{Y}$, lonizing and nonionizing radiation in pregnancy. In: Koren G, editors. Maternal-fetal toxicology: a clinician's guide, 3rd ed. New York, NY: Marcel Dekker, 2001. p. 603-51.

9. Amini Homa, Paul S Casamassimo. Prenatal dental care: A review. General Dentistry. 2010:176-180.

10. Katz VL, Prenatal care. In: Scott JR, Gibbs RS, Karlan BY, Haney AF, editors. Danforth's Obstetrics and Gynecology. 9th ed. Philadelphia: Lippincott, Williams \& Wilkins; 2003. p. 43-8.

11. Wali A, Siddiqui TM, Hameed HA, Kath H. Knowledge, attitude, practice of dental surgeons regarding dental radiographs in pregnant women in the city of Karachi. IJDR 2017; 2: 68-72. (Crossref)

12. Prasad M, Gupta R, Patthi B, et al. Imaging More Imagining less: An Insight into Knowledge, Attitude and Practice Regarding Radiation Risk on Pregnant Women among Dentists of Ghaziabad - A Cross Sectional Study. Journal of Clinical and Diagnostic Research : JCDR. 2016;50:20-5. (Crossref)

13. Livingston HM, Dellinger TM, Holder R. Considerations in the management of the pregnant patient. Spec Care Dentist 1998;18:183-8. (Crossref)

14. Braimoh OB, llochonwu NA. Knowledge of dental dentists on the management of oral conditions in pregnancy in South Nigeria. Eur J Gen Dent 2014;3:150-4. (Crossref)

15. Zanata RL, Fernandes KB, Navarro PS. Prenatal dental care: evaluation of professional knowledge of obstetricians and dentists in the cities of Londrina/PR and Bauru/SP, Brazil, 2004. J Appl Oral Sci. 2008;16:194-200. (Crossref)

16. Pina PM, Douglass J. Practices and opinions of Connecticut general dentists regarding dental treatment during pregnancy. Gen Dent 2011;59:25-31.

17. George A, Shamim S, Johnson M, Dahlen H, Ajwani S, Bhole S, Yeo AE. How do dental and prenatal care dentists perceive dental care during pregnancy? Current evidence and implications. Birth. 2012;39:238-47. (Crossref)

18. Vehmas T. Do radiologists' radiation-related opinions predict their fluoroscopy doses? Br J Radiol 2003;76:653-55. (Crossref) 